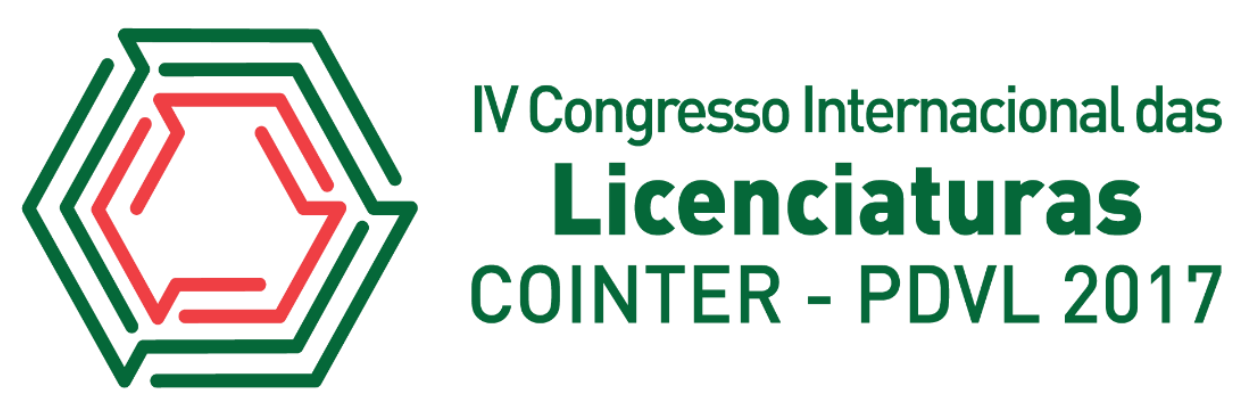

\title{
UMA ANÁLISE DA EDUCAÇÃO AMBIENTAL NO CURRÍCULO DAS ESCOLAS PÚBLICAS DO MUNICÍPIO DE DEPUTADO IRAPUAN PINHEIRO-CE.
}

\author{
Apresentação: Pôster \\ Francisco Deynison Lopes Pinheiro ${ }^{1}$; Caroline Leal Rodrigues Soares ${ }^{2}$; Caio Cézar Oliveira \\ de Lucena ${ }^{3}$; Pedro Silvino Pereira ${ }^{4}$; Antonia Eliene Duarte ${ }^{5}$
}

\section{Introdução}

O dilema ambiental é resultante do modelo de sociedade que encoraja valores consumistas, e como consequência desse consumo, milhares de toneladas de lixo são geradas diariamente. O maior objetivo é tentar criar uma nova mentalidade com relação a como usufruir os recursos oferecidos pela natureza, gerando assim um novo hábito de convívio, buscando estabelecer um elo entre o homem e o meio. Sendo assim, este estudo buscou analisar a influência da educação ambiental desenvolvida nas escolas públicas do município de Deputado Irapuan Pinheiro-Ce, discutindo sua relevância e compreendendo as principais dificuldades e desafios enfrentados pela Educação Ambiental no Fundamental e Médio. Durante a execução do trabalho, foram utilizados três procedimentos de coleta de dados: observação de projetos em desenvolvimento; aplicação de questionário e análise do projeto pedagógico de curso (PPC). A relevância dessa pesquisa se dá pela necessidade de conscientização, já nas séries iniciais do ensino infantil e fundamental, promovendo uma educação ambiental adequada e promissora, gerando cidadãos mais conscientes no futuro.

\section{Fundamentação Teórica}

A preocupação com as questões ambientais vem sendo difundida para o público há muito tempo, infelizmente pesquisas, fatos, mudanças na fauna e flora não foram suficientes para prever e prevenir um problema que vinha crescendo há décadas de maneira silenciosa. Contudo, pouco se

\footnotetext{
${ }^{1}$ Pós-Graduação em Ensino de Biologia e Química, Universidade Regional do Cariri, duarte105@yahoo.com.br

${ }^{2}$ Licenciatura em Ciências Biológicas, Universidade Federal da Paraíba, carolsoaresbiologia@gmail.com

${ }^{3}$ Licenciatura em Ciências Biológicas, Universidade Federal da Paraíba, caiocezarjp@gmail.com

${ }^{4}$ Licenciatura em Ciências Biológicas, Universidade Regional do Cariri, pedro.sillvino@gmail.com

${ }^{5}$ Doutorado, Universidade Regional do Cariri, duarte105@yahoo.com.br
} 
fala em educação ambiental hoje, o público que deveria ser enrraizado na educação ambiental, na maioria das vezes é mediada de maneira branda e superficial.

Com relação a interdisciplinaridade, multidisciplinaridade e transdisciplinaridade, estão intimamente ligada a educação ambiental, pois o tema não é restrito por exemplo a área de ciências da natureza, mais sim coletivamente conectada as outras áreas do conhecimento (MEC, 2016).

Vale salientar também a importância de um currículo escolar condizente com a realidade do aluno e também atual, decorrente das mudanças climáticas do planeta. Nas escolas estudadas, oralmente, enfatiza muito a questão da inserção da educação ambiental no plano de curso, plano de disciplina e projeto político de curso (PPC), por ser um tema transversal e importantíssimo para os discentes. No entanto o que se percebe no contexto, são ações fragmentadas, que era para ser na verdade em forma de uma aprendizagem cooperativa.

A escola é um espaço privilegiado para estabelecer conexões e informações, como uma das possibilidades para criar condições e alternativas que estimulem os alunos a terem concepções e posturas cidadãs, cientes de suas responsabilidades e, principalmente, perceberem-se como integrantes do meio. A educação formal continua sendo um espaço importante para o desenvolvimento de valores e atitudes comprometidas com a sustentabilidade ecológica e social (LEITE et al., 2013).

Respaldando também que os Parâmetros Curriculares Nacionais (PCNs) e as resoluções do Conselho Nacional de Educação (CNE) reconhecem a Educação Ambiental como uma temática a ser inserida no currículo de maneira diferenciado.

Diante do desenvolvimento do projeto nas instituições pesquisadas, notoriamente percebeuse o quanto é importante a educação ambiental não apenas como adição no currículo escolar, mais sim, como um tema transversal amplo e fundamentado, na escola, sendo a mesma enraizada no ensino formal, desde o ensino infantil ao médio.

\section{Metodologia}

Foram realizadas visitas às escolas do município de Deputado Irapuan Pinheiro-Ce, situada a $223 \mathrm{~km}$ de distância do município de Crato-Ce. As instituições de ensino para pesquisa foram divididas em dois eixos: fundamental e médio.

As coletas de dados foram realizadas através de: observação de projetos em desenvolvimento ligados a educação ambiental; aplicação de questionário de 10 questões objetivas 
e subjetivas e mais 2 questões extras, preferencialmente, aos docentes orientadores de temas transversais ou de projetos dentro ou fora da instituição de ensino; análise do plano de curso.

\section{Resultados e Discussões}

Com base nos resultados, notou-se que os docentes questionaram sobre a falta de ferramentas de suporte, onde o próprio livro didático é ausente de conteúdos relacionados à questão ambiental, se fazendo necessário outras metodologias com outros materiais que poderiam auxiliar, mas as escolas pesquisadas não disponibilizam, tornando o trabalho ainda mais difícil no desenvolvimento de projetos intramuros e extramuros. Além que, falta uma maior cooperação e sensibilização por parte do corpo escolar em colocar em prática ações que contribuam para a melhoria do meio.

Diante da observação do PPC, foi constatado em alguns casos, a falta de espaço para uma dedicação ampla e concreta sobre hábitos ambientalmente sustentáveis. Dessa maneira a educação ambiental tende a ser ensinada superficialmente para os discentes, deixando uma aprendizagem sem raízes e com consequências no presente e futuro. As questões ambientais são mediadas de maneira branda e confusa aos discentes, pois sustentam apenas que é necessário preservar o ambiente. Assim, estes acabam sendo apenas ouvintes e não praticantes, quando deveriam ser estimulados através de atividades e projetos a exercer essa consciência a partir de sua realidade e comunidade (DIAS, 2004). Os resultados são expostos dos gráficos abaixo.

Gráfico 1: Sexo dos professores que participaram da pesquisa, escola A e B respectivamente. Fonte:
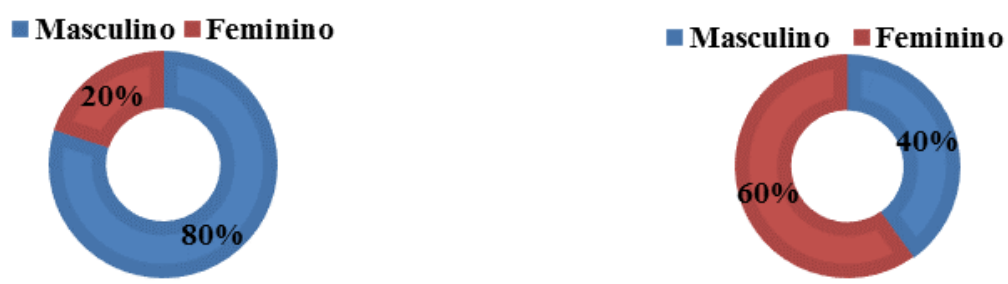

Própria

Gráfico 2: A escola em que trabalha desenvolve projetos na área ambiental? Quais? Fonte: Própria.
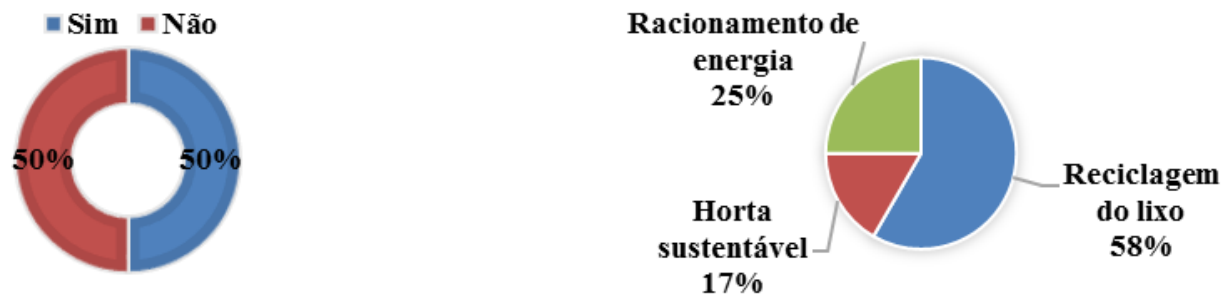

Gráfico 3: Você considera importante a implantação da temática ambiental no curriculo escolar? Porque? Fonte: 

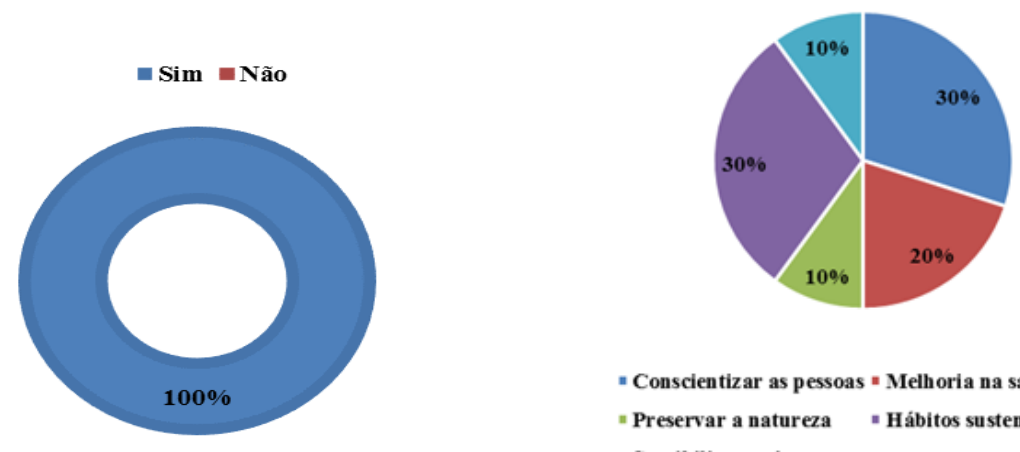

" Conscientizar as pessoas " Melhoria na saúde

" Preservar a natureza " Hábitos sustentáveis

" Sensibilizar os jovens

Gráfico 4: Os professores são incentivados e motivados para estarem desenvolvendo pequenos projetos ou atividades ambientais com os alunos? De que forma? Fonte: Própria.
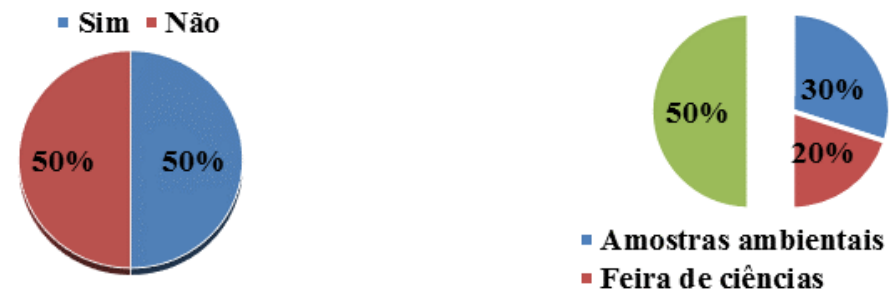

Gráfico 5: Os professores realizam atividades com os alunos fora da escola para trabalhar a realidade local sobre as questões ambientais? De que forma? Fonte: Própria.
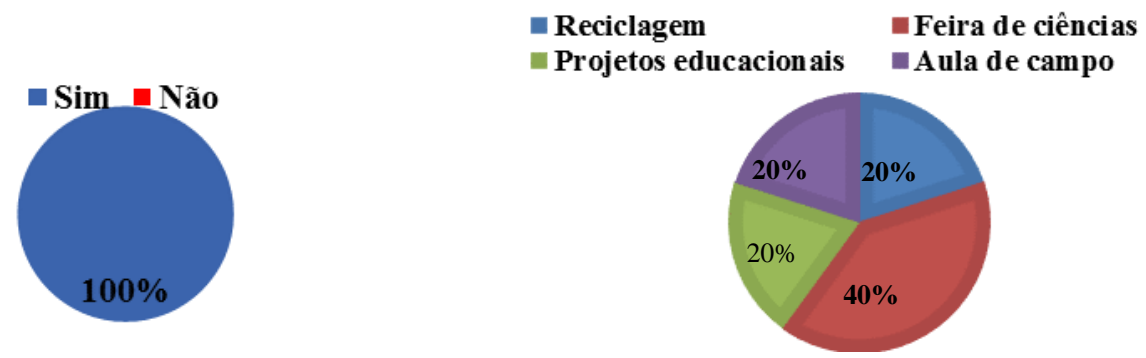

Apesar da maior parte dos educadores conseguirem conceituar educação ambiental e desenvolvimento sustentável. Alguns profissionais nas duas escolas afirmaram saber o significado, não souberam definir desenvolvimento sustentável ou o fizeram de forma inadequada, demonstrando assim, que nem todos os professores têm conhecimento necessário para trabalhar a educação ambiental com seus discentes, necessitando de mais preparo por meio de cursos e treinamentos.

Os professores das duas escolas consideram relevante a inclusão da educação ambiental no currículo escolar, encontram-se raramente estimulados para executarem os projetos, tanto os profissionais da Escola $\mathrm{A}$ como a $\mathrm{B}$, já que os recursos financeiros são limitados para o desenvolvimento de trabalhos nessa área, mas apresentam vontade de fazer, procuram executar atividades diferentes com os alunos, reforçar o conteúdo dos livros didáticos, inovar propostas de acordo com suas possibilidades, como por exemplo: dar aula sobre a preservação da Caatinga, apresentando as desvantagens do lixão a céu aberto; passear nas ruas próximas a escola, para 
mostrar os riscos que os lixos espalhados trazem para a saúde das pessoas, pela falta de conscientização, educação e sensibilização ambiental.

Tal situação faz-se necessário que sejam proporcionados aos docentes, mais formações continuadas ou cursos preparatórios que promovam melhores condições, para que possam trabalhar temas transversais e atividades voltadas para educação ambiental, conduzindo uma didática sustentada com materiais didáticos, paradidáticos e projetos que incentivem a reflexão sobre as questões ambientais e a construção de uma cidadania crítica (PELICIONI; PHILIPPI JUNIOR, 2007).

\section{Conclusões}

Com base nesse trabalho, conclui-se que:

$\checkmark$ Na maioria das escolas os professores entendem de maneira rarefeita o conceito de educação ambiental, porém o suporte que deveria ser dado aos mesmos, muitas vezes fica à desejar.

$\checkmark$ É indispensável um método educativo fundamentado e ajustado no currículo escolar

$\checkmark$ Desenvolver um trabalho de educação ambiental trans, multi e interdisciplinar e coerente no contexto escolar é possível e necessário nos dias atuais.

\section{Referências}

DIAS, G. F. Educação Ambiental: princípios e práticas. 9a ed. São Paulo. Gaia, 2004.

LEITE, I. A.; MORAIS, A. M.; do Ó, K. D. S.; LEITE, C. A. Principal ferramenta na formação de uma consciencia coletiva voltada para uma vida sustentável. Biodiversidade, v. 14, n. 1, p. 161$167,2015$.

MEC - Ministério do meio ambiente. Conceitos de Educação Ambiental: Disponível em: < http://www.mma.gov.br/educacao-ambiental/politica-de-educacao-ambiental. > Acesso em: 20 abril 2016.

PELICIONI, M. C. F.; PHILIPPI JUNIOR, A. Educação Ambiental: Em diferentes espaços. 1. ed. São Paulo: Signus, p. 203-597, 2007. 